Published in final edited form as:

Sep Purif Technol. 2014 November 5; 136: 74-80. doi:10.1016/j.seppur.2014.08.020.

\title{
Aqueous Two-Phase Systems formed by Biocompatible and Biodegradable Polysaccharides and Acetonitrile
}

\author{
Gustavo de Brito Cardoso ${ }^{a}$, Isabela Nascimento Souza ${ }^{a}$, Matheus M. Pereira ${ }^{b}$, Mara G. \\ Freire $^{\mathrm{b}}$, Cleide Mara Faria Soares ${ }^{\mathrm{a}, \mathrm{c}}$, and Álvaro Silva Lima ${ }^{\mathrm{a}, \mathrm{c},{ }^{*}}$ \\ aPrograma de Pós-Graduação em Engenharia de Processos, Universidade Tiradentes, Av. \\ Murilo Dantas 300, Farolândia. CEP: 49032-490, Aracaju-SE, Brazil \\ bDepartamento de Química, CICECO, Universidade de Aveiro, 3810-193 Aveiro, Portugal \\ Instituto de Tecnologia e Pesquisa. Av. Murilo Dantas, 300. CEP: 49032-490, Aracaju - SE, \\ Brazil
}

\begin{abstract}
In this work, it is shown that novel aqueous two-phase systems can be formed by the combination of acetonitrile and polysaccharides, namely dextran. Several ternary phase diagrams were determined at $25^{\circ} \mathrm{C}$ for the systems composed of water + acetonitrile + dextran. The effect of the dextran molecular weight $\left(6,000,40,000\right.$ and 100,000 g.mol $\left.{ }^{-1}\right)$ was ascertained toward their ability to undergo liquid-liquid demixing. An increase in the dextran molecular weight favors the phase separation. Furthermore, the effect of temperature $\left(25,35\right.$ and $\left.45^{\circ} \mathrm{C}\right)$ was evaluated for the system constituted by the dextran of higher molecular weight. Lower temperatures are favorable for phase separation since lower amounts of dextran and acetonitrile are required for the creation of aqueous two-phase systems. In general, acetonitrile is enriched in the top phase while dextran is majorly concentrated in the bottom phase. The applicability of this new type of two-phase systems as liquid-liquid extraction approaches was also evaluated by the study of the partition behavior of a well-known antioxidant - vanillin - and used here as a model biomolecule. The optimized conditions led to an extraction efficiency of vanillin of $95 \%$ at the acetonitrile-rich phase.
\end{abstract}

\section{Keywords}

aqueous two-phase system; acetonitrile; dextran; vanillin; extraction

\section{Introduction}

Aqueous two-phase systems (ATPS) are widely applied in biotechnology for the isolation and purification of enzymes such as lipase [1-3], antioxidants, namely rutin [4] and gallic acid [5], alkaloids, such as theobromine, theophyline, nicotine and caffeine [6], antibiotics, for instance tetracycline $[7,8]$, and antibodies $[9,10]$. The main advantages of ATPS rely on their scale-up possibility, on the rapid mass transfer and phase equilibrium, possibility of a continuous processing, low energy requirements, among others [11].

\footnotetext{
*To whom correspondence should be addressed: alvaro_lima@unit.br. Phone: +55 7932182115. Fax: +55 7932182190.
} 
ATPS are usually formed by mixing two polymers in aqueous media, for instance polyethylene glycol (PEG) and dextran [12,13] or PEG and maltodextrin [14], or by one polymer and one salt, such as PEG and phosphate-based salts [15-17] or PEG and citratebased salts $[18,19]$. However, some other pairs of phase-forming components can be used in the creation of alternative ATPS, such as alcohol + salt [20], ionic liquid + salt [21-23], ionic liquid + PEG [24,25] and ionic liquid + carbohydrate [26].

Previously we have also demonstrated that alternative aqueous biphasic systems can be created by combining acetonitrile and carbohydrates (monosaccharides and disaccharides) [27] as well as with polyols [28]. In this context, we attempted now the formation of novel ATPS formed by acetonitrile and polysaccharides, namely dextran.

Dextran is a water soluble biopolymer produced by a variety of lactic acid bacteria, such as Leuconostoc sp., and which presents two valuable properties: biodegradability and biocompatibility [29]. The chemical structure of dextran is predominantly formed by $95 \%$ of linear $a-(1 \rightarrow 6)$ linkages as the main backbone and $5 \%$ of $a-(1 \rightarrow 3)$ branch linkages [30]. This homopolymer of glucose has several targeted industrial applications, varying from food, cosmetic, and pharmaceutical to oil drilling industries [31].

Acetonitrile $\left(\mathrm{CH}_{3} \mathrm{CN}\right)-\mathrm{ACN}$ - is an interesting solvent due to its properties; it is aprotic and strongly polar and is obtained as a by-product from the manufacture of acrylonitrile [32]. ACN is widely used by industry in the production of perfumes, rubber products, pesticides or pharmaceuticals [33], and in chromatography processes as a mobile phase in high performance liquid chromatography - HPLC [34,35]. This solvent is miscible with water in all proportions [36] and its molecules are unable to strongly associate with themselves leaving a hydrogen-bond network formed by water [37,38].

The aim of the present work is to study novel aqueous two-phase systems based on acetonitrile and several dextrans of different molecular weights. The ternary phase diagrams were determined at $25^{\circ} \mathrm{C}$ and the effect of the polysaccharide molecular weight was evaluated. Moreover, the effect of temperature $\left(25,35\right.$ and $\left.45^{\circ}\right)$ through the phase diagrams behavior was also addressed for the ATPS constituted by the dextran of higher molecular weight. These systems were also ascertained on what regards their applicability on extraction routes, and in particular on the extraction of a well-known antioxidant, vanillin (4-hydroxy-3-methoxybenzaldehyde). Vanillin is the major flavor constituent of natural vanilla - Vanilla plantifolia, extracted at a rate of 12,000 ton/year [39]. Vanillin is widely used as a flavoring material in confectionery, food products, beverages, perfumes and in pharmaceutical preparations [40]. Natural vanillin costs between 1,200 and 4,000 USD/kg, while synthetic vanillin costs around $15 \mathrm{USD} / \mathrm{kg}$ [41]. However, the chemical process usually leads to a low quality vanillin that further requires a sensitive extraction and purification procedure [42], and for which ATPS can be foreseen as an alternative approach. 


\section{Material and Methods}

\subsection{Materials}

The ATPS studied in this work were formed by dextran from Leuconostoc spp. ( $M_{w}=$ 100.000 g.mol ${ }^{-1}-$ Dx-100; 40.000 g.mol ${ }^{-1}-$ Dx-40; and 6.000 g.mol ${ }^{-1}-$ Dx-6) and acetonitrile. Dextran and acetonitrile (purity of $99.9 \mathrm{wt} \%$ ), as well as vanillin (>99 wt\% pure) were purchased from Sigma-Aldrich. The chemical structures of the phase-forming components of the ATPS studied and of the target biomolecule used in the partitioning experiments are shown in Figure 1. Distilled and deionized water was used in all experiments.

\subsection{Phase diagrams and tie-lines}

The ternary phase diagrams for water, acetonitrile and the different molecular weight dextran were determined at 25,35 and $45( \pm 1)^{\circ} \mathrm{C}$ in atmospheric pressure by the cloud point titration method [43]. Pure acetonitrile (since it is water soluble in the whole composition range and no precipitation effects were observed during the determination of the liquidliquid saturation curves) and a solution of dextran (Dx-100, Dx-40 and Dx-6) at $20 \mathrm{wt} \%$ (a concentration close and below their saturation limit in water at room temperature) was previously prepared and used for the determination of the binodal curves. Repetitive dropwise addition of pure acetonitrile to the aqueous solution of dextran was carried out until the detection of a cloudy solution, followed by the drop-wise addition of ultra-pure water until the inspection of a monophasic region (clear and limpid solution). These additions were carried out under continuous stirring and the saturation curves were determined gravimetrically within $\pm 10^{-4} \mathrm{~g}$.

The tie-lines (TLs) were obtained through a gravimetric method originally described by Merchuk et al. [44]. Several mixtures at the biphasic region of the ternary systems were prepared (total of $5 \mathrm{~g}$ ), vigorously stirred, and allowed to reach equilibrium and phase separation, for a minimum of $18 \mathrm{~h}$ at 25,35 and $45( \pm 1)^{\circ} \mathrm{C}$. The temperature was maintained by means of a temperature-controlled water-bath. Initially, aqueous solutions of each dextran were prepared followed by the addition of pure ACN to reach a specific mixture composition. After the equilibration step, the top and bottom phases were carefully separated and weighted within $\pm 10^{-5} \mathrm{~g}$. Each individual TL was determined by the application of the lever-arm rule, which describes the relationship between the weight of the top phase and the overall system weight and composition. For that purpose, the binodal curves were correlated using Eq. 1,

$$
Y=A \exp \left\{\left(B \times X^{0.5}-\left(C \times X^{3}\right)\right\}\right.
$$

where $Y$ and $X$ are the acetonitrile and dextran weight fraction percentages, respectively, and $A, B$ and $C$ are constant values obtained by the fitting of the experimental saturation curve data.

The determination of the TLs, describing the composition of $Y$ and $X$ at the top $(T)$ and bottom phases $(B)-Y_{\mathrm{T}}, Y_{\mathrm{B}}, X_{\mathrm{T}}$ and $X_{\mathrm{B}}$ - was then accomplished by solving a system of four 
equations derived from Eq. 1 [43,44]. The respective tie-line lengths (TLLs) were determined through the application of Eq. 2,

$$
T L L=\sqrt{\left(X_{T}-X_{B}\right)^{2}+\left(Y_{T}-Y_{B}\right)^{2}}
$$

\subsection{Partitioning of vanillin}

Dextran and an aqueous solution of vanillin $\left(0.1 \mathrm{~g} . \mathrm{L}^{-1}\right)$ were initially mixed, and after the complete homogenization, acetonitrile was added to reach the chosen mixture composition. Each ATPS (total of $5 \mathrm{~g}$ ) was prepared in glass tubes. After the complete mixing of all components, for a given mixture composition, each tube was immersed in a thermostatic water bath from 5 to $45( \pm 1)^{\circ} \mathrm{C}$ for at least $18 \mathrm{~h}$. After equilibration, both phases were separated for the quantification of vanillin. At least three independent replicates were made and the average partition coefficients and associated standard deviations were therefore determined.

The concentration of vanillin at each aqueous phase was quantified through UVspectroscopy, using a Varian Cary 50 Bio UV-Vis spectrophotometer, and at a wavelength of $280 \mathrm{~nm}$ using a calibration curve previously established. At the concentration of vanillin used, dilutions in the order of 1:50 (v:v) were carried out in distilled water. At these dilutions there are no interferences by the phase-forming components at $280 \mathrm{~nm}$ in the quantification of vanillin. Therefore, no blanks were needed for the vanillin quantification at the dilutions carried out.

The partition coefficient of vanillin was determined taking into account the concentration of the antioxidant in each phase and according to,

$$
K_{V a n}=\frac{C_{V a n, T}}{C_{V a n, B}}
$$

where $K_{\mathrm{van}}$ is the partition coefficient of vanillin, $C$ represents the vanillin concentration, and the subscripts $\mathrm{T}$ and B symbolize the top (acetonitrile-rich) and bottom (dextran-rich) phases, respectively.

The percentage extraction efficiencies of vanillin, $E E_{\mathrm{Van}} \%$, were defined as the percentage ratio between the amount of vanillin in the acetonitrile-rich phase and that in the total mixture, according to:

$$
E E_{v a n} \%=\frac{w_{v a n, T}}{w_{v a n, T}+w_{v a n, B}} \times 100
$$

where $w_{\text {van, } \mathrm{T}}$ and $w_{\text {van,B }}$ are the weight of vanillin in the acetonitrile-rich (top) phase and in the dextran-rich (bottom) phases, respectively. 


\section{Results and Discussion}

The effect of different molecular weights of dextran towards the phase separation in acetonitrile-aqueous solutions was firstly addressed through the determination of the respective phase diagrams at $25{ }^{\circ} \mathrm{C}$. Then, the impact of temperature was evaluated with a fixed ATPS and for which the respective phase diagrams were determined at 25, 35 and 45 ${ }^{\circ} \mathrm{C}$. Further, the potentiality of these systems for the extraction of biomolecules, using vanillin as a model antioxidant, was assessed. The effects of the dextran and ACN concentrations as well as of temperature were also evaluated in what concerns the vanillin partitioning.

\subsection{Ternary Phase Diagrams}

Three high molecular weight dextrans (Dx-100, Dx-40 and Dx-6) were used in combination with acetonitrile in aqueous media, and the respective phase diagrams were determined at $25^{\circ} \mathrm{C}$ and atmospheric pressure. The binodal curves experimentally determined are depicted in Figure 2 in molality units (mole of $\mathrm{ACN}$ or mole or dextran per $\mathrm{kg}$ of solvent) for an enhanced understanding on the impact of the distinct dextrans through the formation of ATPS. The respective experimental weight fraction data are provided in the Supporting Information.

The analysis of Figure 2 reveals a strong displacement of the binodal curves towards the origin in the following order: Dx-6 > Dx-40 > Dx-100. In general, the higher the molecular weight of the polysaccharide the more able it is to form two aqueous rich phases with acetonitrile. These results corroborate those found by Lima and co-workers [27] where higher molecular weight carbohydrates, namely monosaccharides and disaccharides, result in a higher ability for phase separation. The increase of the molecular weight of dextran leads to an increase on the number of hydroxyl groups per mole of biopolymer. Indeed, and as previously discussed by Freire and co-workers [26], the number of hydroxyl groups present in carbohydrates as phase-forming components of ATPS is directly associated with its capability to hydrogen-bond with water and, therefore, to act as sugaring-out species. In the same context, Lima and co-workers [28] also demonstrated that polyols with more hydroxyl groups are more able to form ATPS with acetonitrile. In addition, as the molecular weight of the polysaccharide increases, the binodal curves shift to lower dextran and ACN concentrations. This is a main result of the decreasing solubility of the dextran in water with an increase in its molecular weight. Therefore, species with low affinity for water are also more able to be phase separated and to form an ATPS. This tendency is in agreement with other experimental results for ATPS composed of polymers and ionic liquids [45], polymers and salts [46] or dextran and a polymer [47].

Figure 3 shows a general comparison between the strongest sugaring-out agents previously reported (a dissacharide and a polyol) [29,30], and the dextran with the highest molecular weight determined here, on their ability to form ATPS with acetonitrile. In fact, it is clearly seen that polysaccharides perform as better sugaring-out agents when compared with carbohydrates of lower molecular weight and polyols. In summary, lower amounts of dextran are required to induce the liquid-liquid demixing when compared to disaccharides 
and polyols and which can be foreseen as a major advantage towards the sustainability concept.

Finally, the effect of temperature on the phase diagrams behavior was evaluated with the ATPS formed by Dx-100 and ACN. The binodal curves obtained at 25,35 and $45^{\circ} \mathrm{C}$ are presented in Figure 4. The binodal curves reveal that an increase in temperature decreases the immiscibility region. In general, lower temperatures are favorable for phase-separation since lower amounts of ACN and dextran are required. Dextran is more water-soluble at higher temperatures and thus it is more difficult to create an ATPS. The pattern observed is in close agreement with that observed in dextran-polymer [48].and in ionic-liquidcarbohydrate ATPS [49].

All experimental binodal data were fitted using the empirical relationship described by Eq. 1. The fitted parameters $A, B$ and $C$ (estimated by least-squares regression), and the corresponding standard deviations and regression coefficients are presented in Table 1 . As can be seen by the gathered correlation coefficients, Eq. 1 provides an accurate description of the experimental saturation curves. To complete the phase diagrams, several TLs and respective TLLs were additionally calculated and their values are reported in Table 2.

\subsection{Partitioning of vanillin}

In order to evaluate the potential of the studied ATPS to be applied as extractive systems, vanillin was thorough used. The partition coefficients and the extraction efficiencies of vanillin at the acetonitrile-rich phase were determined at different compositions and at several temperatures.

Contrarily to more conventional ATPS composed of polymer-salt or polymer-polymer combinations, it should be remarked that the dextran-ACN-based ATPS proposed here allow the simple recovery of the phase-forming components since ACN and water are volatile and the polysaccharide can be easily recovered after an evaporation step. This opportunity certainly leads to further investigations on these systems as alternative extraction/separation techniques when foreseeing more sustainable processes with a combined recovery and reuse of the ATPS phase-forming components.

3.2.1. Influence of the dextran molecular weight-Two-phase systems composed of $15 \mathrm{wt} \%$ of dextran and $30 \mathrm{wt} \%$ of ACN, and for the 3 different molecular weights dextran (Dx-6; Dx-40 and Dx-100), were used to study the partitioning behavior of vanillin. All these results were obtained at $25^{\circ} \mathrm{C}$. The partition coefficient $\left(K_{\mathrm{van}}\right)$ and extraction efficiency of vanillin $\left(E E_{\mathrm{van}} \%\right.$ ) for the top (acetonitrile-rich) phase are shown in Figure 5 and the corresponding numeric values are reported in the Supporting Information. Figure 5 allows the inspection through the influence of the dextran molecular weight on the vanillin partitioning among the two phases.

For Dx-6 and Dx-40, vanillin displays a similar partitioning behavior between the coexisting phases $\left(K_{v a n} \approx 1.7-1.8\right)$. Nevertheless, the use of Dx-100 leads to a preferentially partitioning of vanillin for the ACN-rich phase $\left(K_{v a n}>3.0\right)$. In general, an increase on the molecular weight of dextran induces an increase on the partition coefficient of vanillin, 
particularly seen with Dx-100. This effect can be explained by a volume exclusion model [50], where the intermolecular spaces in the dextran-rich phase are reduced with the increase on the molecular weight, and consequently, vanillin migrates for the top phase (ACN-rich phase). Other authors also observed the volume exclusion effect using polymers as polyethylene glycol in the partition behavior of bromelin [51] and protease [52]. However, and as previously shown by us $[29,30]$, this increase on the partition coefficients for the ACN-rich phase can be also a result of a sugaring-out phenomenon of the polysaccharide over the target biomolecule.

The extraction efficiency of vanillin in the ACN-rich phase ranges between 77 and $88 \%$ with higher values achieved with Dex-100. In summary, the highest partition coefficient and recovery of vanillin in the ACN-rich phase was observed with the system composed of Dx-100, the higher molecular weight polysaccharide investigated.

3.2.2. Influence of the dextran/acetonitrile concentrations-To initially evaluate the effect of the dextran concentration through the vanillin partitioning, a series of ATPS containing variable concentrations of Dex-100 (from 15-20 wt\%) at fixed amounts of ACN $(25,30$ and $35 \mathrm{wt} \%)$ were prepared. The results obtained are depicted in Figure 6 and in the Supporting Information.

Although the differences are not very significant, in general, an increase in the dextran concentration leads to a decrease in the partition coefficients and extraction efficiencies of vanillin, been this effect more pronounced with the higher ACN content. Therefore, lower amounts of dextran are enough to lead to high extraction efficiencies and which represent a decrease on the economic costs associated to these ATPS. The recovery values of vanillin at the ACN-rich phase range between 79 and $95 \%$ and are vely close to those found by us (98-99\%) using ATPS constituted by alcohols and strong salting-out species and high charge density potassium phosphate salts [20].

At all concentrations of dextran it is observed a maximum value either on the partition coefficients or on the extraction efficiencies that occurs at $30 \mathrm{wt} \%$ of ACN. It seems thus that there is a multibalanced phenomenon governing the partitioning trend of vanillin.

3.2.3. Influence of temperature-In the previous sections it was demonstrated that by choosing a high molecular weight dextran (Dx-100) at a concentration ranging between $15-20 \mathrm{wt} \%$, vanillin can be effectively separated and concentrated into the top phase.

Therefore, the effect of temperature was also evaluated at temperatures varying between 5 and $45{ }^{\circ} \mathrm{C}$, for the common mixture composition of $30 \mathrm{wt} \%$ of ACN $+18 \mathrm{wt} \%$ of Dx- 100 . The results obtained are depicted in Figure 7 whereas the respective values are presented in the Supporting Information.

At all temperatures, vanillin preferentially migrates for the top phase $\left(1<K_{\mathrm{van}}<11\right)$. However, these values are somewhat lower than those observed with ATPS composed of ionic liquids + potassium phosphate $\left(7<K_{\text {van }}<50\right)[53]$ and of acetonitrile + polyols $(7<$ $\left.K_{\mathrm{van}}<67\right)$ [28]. However, the partition coefficients obtained in this work are similar to those 
reported by Lima and co-workers [27] using ATPS formed by acetonitrile and carbohydrates $\left(3<K_{\mathrm{van}}<10\right)$.

The results obtained indicate that temperature influences the vanillin partitioning. This effect can be divided into two parts: (i) between 5 and $25^{\circ} \mathrm{C}$ in which the $K_{\text {van }}$ reaches the maximum value (11.26); (ii) and between 25 and $45^{\circ} \mathrm{C}$ in which the partition coefficient of vanillin decreases with an increase in temperature. Similarly to the results on the vanillin partitioning in ionic-liquid-salt ATPS [53] it was also observed here a maximum value in the partition coefficient as a function of temperature. This maximum as a function of temperature suggests that the partition phenomenon is driven by opposite effects resulting from enthalpic and entropic contributions as previously discussed [53]. The extraction efficiency of vanillin for all system ranges between 70 and $95 \%$ and a similar trend with temperature is observed when compared with the partition coefficients.

\section{Conclusions}

In this work, novel aqueous two-phase systems based on acetonitrile and dextran were proposed. The binodal curves, which define the mono- and biphasic regimes, were determined at $25^{\circ} \mathrm{C}$ and at atmospheric pressure for three dextran polysaccharides of different molecular weight, namely 6,000, 40,000 and 100,000 mol. $\mathrm{kg}^{-1}$. In general, the higher the molecular weight of dextran, the higher is the ability of the system to undergo phase separation. The effect of temperature was also evaluated. Higher temperatures are not favorable for inducing the formation of ATPS. Lower amounts of dextran and acetonitrile are required to form an ATPS at lower temperatures.

The novel ATPS were also evaluated in what concerns their potential for extraction purposes. Vanillin was used as a model antioxidant or bioactive substance. In all situations, vanillin preferentially migrates for the acetonitrile-rich phase. The higher partition coefficients and extraction efficiencies of vanillin at the acetonitrile-rich phase were observed with the dextran with the higher molecular weight (Dx-100) and at $25^{\circ} \mathrm{C}$. The highest value of $K_{\mathrm{van}}(11.3)$ and $E E_{\mathrm{van}} \%(95 \%)$ was found using an ATPS composed of 18 $\mathrm{wt} \%$ of Dx-100 and $30 \mathrm{wt} \%$ of acetonitrile at $25^{\circ} \mathrm{C}$.

\section{Supplementary Material}

Refer to Web version on PubMed Central for supplementary material.

\section{Acknowledgments}

The authors are thankful to Fundação de Amparo a Pesquisa e Inovação Tecnológica do Estado de Sergipe FAPITEC/SE for the financial support and scholarship of G.B. Cardoso, and CNPq for the scholarship of I.N Souza. The authors thank Fundação para a Ciência e a Tecnologia (FCT) for the projects PTDC/QUI-QUI/ 121520/2010 and Pest-C/CTM/LA0011/2013. M.G. Freire acknowledges the European Research Council (ERC) for the Grant ERC-2013-StG-337753. The authors also acknowledge the financial support from Coordenação de Aperfeiçoamento de Pessoal de Nível Superior - Capes for the PhD grant (2740-13-3) of M.M. Pereira. 


\section{References}

[1]. Ventura SPM, Lemos R, Barbosa JMP, Soares CMF, Lima AS, Coutinho JAP. Production and purification of an extracellular lipolytic enzyme using ionic liquids-based aqueous two-phase systems. Green Chem. 2012; 14:734-740.

[2]. Barbosa JMP, Souza RL, Fricks AT, Zanin GM, Soares CMF, Lima AS. Purification of lipase produced by a new source of Bacillus in submerged fermentation using an aqueous two-phase system. J. Chromatogr. B. 2011; 879:3853-3858.

[3]. Souza RL, Barbosa JMP, Zanin GM, Lobão MWN, Soares CMF, Lima AS. Partitioning of porcine pancreatic lipase in a two-phase systems of polyethylene glycol/potassium phosphate aqueous. Appl. Biochem. Biotech. 2010; 16:288-300. R.L.

[4]. Reis IAO, Santos SB, Pereira FDS, Sobral CRS, Freire MG, Freitas LS, Soares CMF, Lima AS. Extraction and recovery of rutin from acerola waste using alcohol-sal-based aqueous two-phase systems. Separ. Sci. Technol. 2014 In press.

[5]. Cláudio AFM, Ferreira AM, Freire CSR, Silvestre AJD, Freire MG, Coutinho JAP. Optimization of the gallic acid extraction using ionic-liquid-based aqueous two-phase systems. Sep. Purif. Technol. 2012; 97:142-149.

[6]. Passos H, Trindade MP, Vaz TSM, Costa LP, Freire MG, Coutinho JAP. The impact of selfaggregation on the extraction of biomolecules in ionic-liquid-based aqueous two-phase systems. Sep. Purif. Technol. 2013; 108:174-180.

[7]. Pereira JFB, Vicente F, Santos-Ebinuma VC, Araújo JM, Pessoa A, Freire MG, Coutinho JAP. Extraction of tetracycline from fermentation broth using aqueous two-phase systems composed of polyethylene glycol and cholinium-based salts. Process Biochem. 2013; 48:716-722.

[8]. Wang Y, Han J, Xu X, Hu S, Yan Y. Partition behavior and partition mechanism of antibiotics in ethanol/2-propanol-ammonium sulfate aqueous two-phase systems. Sep. Purif. Technol. 2010; 75:352-357.

[9]. Azevedo AM, Gomes AG, Rosa PAJ, Ferreira IF, Pisco AMMOM, Aires-Barros R. Partitioning of human antibodies in polyethylene glycol-sodium citrate aqueous two-phase systems. Sep.Purif. Technol. 2009; 65:14-21.

[10]. Samatou JA, Wentink AE, Rosa PAJ, Azevedo PM, Aires-Barros MR, Bäcker W, Górak A. Modeling of counter current monoclonal antibody extraction using aqueous two-phase systems. Comp. Aided Chem. Eng. 2007; 24:935-940.

[11]. Gündüz U. Viscosity prediction of polyethylene glycol-dextran-water solutions used in aqueous two-phase system. J. Chromatogr. B. 2000; 74:181-185.

[12]. Karakatsanis A, Liakopoulou-Kyriakides M. Comparison of PEG/fractionated dextran and PEG/ industrial grade dextran aqueous two-phase systems for the enzymic hydrolysis of starch. J. Food Eng. 2007; 80:1213-1217.

[13]. Chen JP, Lee MS. Enhanced production of Serratia marcescens chitinase in PEG/dextran aqueous two-phase systems. Enzyme Microb. Tech. 1995; 17:1021-1027.

[14]. Silva LHM, Meirelles AJA. Phase equilibrium in polyethylene glycol/maltodextrin aqueous twophase systems. Carbohyd. Polym. 2000; 42:273-278.

[15]. Silva GMM, Marques DAV, Porto TS, Lima Filho JL, Teixeira JAC, Pessoa-Júnior A, Porto ALF. Extraction of fibrinolytic proteases from Streptomyces sp. DPUA1576 using PEGphosphate aqueous two-phase systems. Fluid Phase Equilibr. 2013; 339:52-57.

[16]. Lima AS, Alegre RM, Meirelles AJA. Partitioning of pectinolytic enzymes in polyethylene glycol/potassium phosphate aqueous two-phase systems. Carbohyd. Polym. 2002; 50:66-68.

[17]. Köhler K, Veide A, Enfors SO. Partitioning of $\beta$-galactosidase fusion proteins in PEG/potassium phosphate aqueous two-phase systems. Enzyme Microb. Tech. 1991; 13:204-209.

[18]. Neves MLC, Porto TS, Souza-Motta CM, Spier MR, Soccol CR, Moreira KA, Porto ALF. Partition and recovery of phytase from Absidia blakesleeana URM5604 using PEG-citrate aqueous two-phase systems. Fluid Phase Equilibr. 2012; 318:34-39.

[19]. Porto TS, Silva GMM, Porto CS, Cavalcanti MTH, Neto BB, Lima-Filho JL, Converti A, Porto ALF, Pessoa A Jr. Liquid-liquid extraction of proteases from fermented broth by PEG/citrate aqueous two-phase system. Chem. Eng. Process. 2008; 47:716-721. A.L.F. 2008.

Sep Purif Technol. Author manuscript; available in PMC 2015 February 25. 
[20]. Reis IAO, Santos SB, Santos LA, Oliveira N, Freire MG, Pereira JFB, Ventura SPM, Coutinho JAP, Soares CMF, Lima AS. Increased signifcance of food waste: selective recovery of addedvalue compounds. Food Chem. 2012; 135:2453-2461. [PubMed: 22980828]

[21]. Ventura SPM, Sousa SG, Serafim LS, Lima AS, Freire MG, Coutinho JAP. Ionic-liquid-based aqueous biphasic systems with controlled ph: the ionic liquid anion effect. J. Chem. Eng. Data. 2012; 57:507-512.

[22]. Neves CMSS, Ventura SPM, Freire MG, Marrucho IM, Coutinho JAP. Evaluation of cation influence on the formation and extraction capability of ionic-liquid-based aqueous biphasic systems. J. Phys. Chem. B. 2009; 113:5194-5199. [PubMed: 19309125]

[23]. Gutowski KE, Broker GA, Willauer HD, Huddleston JG, Swatloski RP, Holbrey JD, Rogers RD. Controlling the aqueous miscibility of ionic liquids: aqueous biphasic systems of water-miscible ionic liquids and water-structuring salts for recycle, metathesis, and separations. J. Am. Chem. Soc. 2003; 125:6632-6633. [PubMed: 12769563]

[24]. Pereira JFB, Ventura SPM, Silva FA, Shahriari S, Freire MG, Coutinho JAP. Aqueous biphasic systems composed of ionic liquids and polymers: a platform for the purification of biomolecules. Sep. Purif. Technol. 2013; 113:83-89.

[25]. Freire MG, Pereira JFB, Francisco M, Rodríguez H, Rebelo LPN, Rogers RD, Coutinho JAP. Insight into the interactions that control the phase behaviour of new aqueous biphasic systems composed of polyethylene glycol polymers and ionic liquids. Chem. Eur. J. 2012; 18:1831-1839. [PubMed: 22223510]

[26]. Freire MG, Louros CLS, Rebelo LPN, Coutinho JAP. Aqueous biphasic systems composed of a water-stable ionic liquid + carbohydrates and their applications. Green Chem. 2011; 13:15361545.

[27]. Cardoso GB, Mourão T, Pereira FM, Fricks AT, Freire MG, Soares CMF, Lima AS. Aqueous two-phase systems based on acetonitrile and carbohydrates and their application to the extraction of vanillin. Sep. Purif. Technol. 2013; 104:106-113.

[28]. Cardoso GB, Souza INS, Mourão T, Freire MG, Soares CMF, Lima AS. Novel aqueous twophase systems composed of acetonitrile and polyols: phase diagrams and extractive performance. Sep. Purif. Technol. 2014; 124:54-60.

[29]. Siddiqui NN, Aman A, Silipo A, Qader SAU. Structural analysis and characterization of dextran produced by wild and mutante strains of Leuconostoc mesenteroides. Carbo. Polym. 2014; 99:331-338.

[30]. Vettori MHPB, Franchetti SMM, Continero J. Structural characterization of a new dextran with a low degree of branching produced by Leuconostoc mesenteroides FT045B dextrasucrase. Carbohyd. Polym. 2012; 88:1440-1444.

[31]. Aman A, Siddiqui NN, Qader SAU. Characterization and potential applications of high molecular weight dextran produced by Leuconostoc mesenteroides AA1. Carbohydr. Polym. 2012; 87:910-915.

[32]. Pollak, P.; Romeder, G.; Hagedorn, F.; Gelbke, HP. Ullmann's encyclopedia of industrial chemistry. sixth ed.. Wiley Online Library; New York: 2000.

[33]. Zhang D, Zhang Y, Wen Y, Hou K, Zhao J. Intrinsic kinetics for the synthesis of acetonitile from ethanol and ammonia over $\mathrm{Co}-\mathrm{Ni} / \mathrm{c}-\mathrm{Al}_{2} \mathrm{O}_{3}$ catalyst. Chem. Eng. Res. Des. 2011; 89:2147-2152.

[34]. Taha M, Teng HL, Lee MJ. Phase diagrams of acetonitrile or (acetone + water + EPPS) buffer phase separation systems at $298.15 \mathrm{~K}$ and quantum chemical modeling. J. Chem. Thermodyn. 2012; 54:134-141.

[35]. Gu Y, Shih PH. Salt-induced phase separation can effectively remove the acetonitrile from the protein sample after the preparative RP-HPLC. Enzyme Microb. Technol. 2004; 35:592-597. P.H.

[36]. Mandal MK, Sant SB, Bhattacharya PK. Dehydration of aqueous acetonitrile solution by pervaporation using PVA-iron oxide nanocomposite membrane. Colloids Surf. A. 2011; 373:1121.

[37]. Piekarski P, Kubalczyk K. Thermochemical properties of ions in acetonitrile-organic cosolvent mixtures at 298.15 K. J. Mol. Liq. 2005; 121:35-40. 
[38]. Takamuku T, Tabata M, Yamaguchi A, Nishimoto J, Kumamoto M, Wakita H, Yamaguchi T. Liquid structure of acetonitrile-water by X-ray diffraction and infrared spectroscopy. J. Phys. Chem. B. 1998; 102:8880-8888.

[39]. Zidi C, Tayeb R, Boukhili N, Dhahbi M. A supported liquid membrane system for efficient extraction of vanillin from aqueous solutions. Sep. Purif. Technol. 2011; 82:36-42.

[40]. Walton NJ, Mayer MJ, Narbad A. Vanillin. Phytochemistry. 2003; 63:505-515. [PubMed: 12809710]

[41]. Dong Z, Gu F, Xu F, Wang Q. Comparasion of four kinds of extraction techniques and kinetics of microwave-assisted extraction of vanillin from Vanilla plantifolia. Food Chem. 2014; 149:5461. [PubMed: 24295676]

[42]. Rao SR, Ravishankar GA. Vanilla flavor: production by conventional and biotechnological routes. J. Sci. Food Agr. 2000; 80:289-304.

[43]. Almeida MR, Passos H, Pereira MM, Lima ÁS, Coutinho JAP, Freire MG. Ionic liquids as additives to enhance the extraction of antioxidants in aqueous two-phase systems. Sep. Purif. Technol. 2014; 128:1-10.

[44]. Merchuk JC, Andrews BA, Asenjo JA. Aqueous two-phase systems for protein separation: studies on phase inversion. J. Chromatogr. B. 1998; 711:285.

[45]. Freire MG, Pereira JF, Francisco M, Rodríguez H, Rebelo LPN, Rogers RD, Coutinho JAP. Insight into the interactions that control the phase behavior of new aqueous biphasic systems composed of polyethylene glycol polymers and ionic liquids. Chem. Eur. J. 2012; 18:1831. [PubMed: 22223510]

[46]. Zafarani-Moattar MT, Sadeghi R. Liquid-liquid equilibria of aqueous two-phase systems containing polyethylene glycol and sodium dihydrogen phosphate or disodium hydrogen phosphate: Experiment and correlation. Fluid Phase Equilib. 2001; 181:95-112.

[47]. Diamond AD, Hsu JT. Phase diagrams for dextran-PEG aqueous two-phase systems at $22^{\circ} \mathrm{C}$. Biotech. Tech. 1989; 3:119-124.

[48]. Grol3mann C, Tintinger R, Zhu J, Maurer G. Aqueous two-phase systems of poly(ethylene glycol) and dextran-experimental results and modeling of thermodynamic properties. Fluid Phase Equilib. 1995; 106:111-138.

[49]. Chen Y, Meng Y, Zhang S, Zhang Y, Liu X, Yang J. Liquidliquid equilibria of aqueous biphasic systems composed of 1-butyl-3-methyl imidazolium tetrafluoroborate + sucrose/maltose + water. J. Chem. Eng. Data. 2010; 55:3612-3616.

[50]. Albertsson, PA. Partition of cell particles and macromolecules. second ed.. Wiley Interscience; New York: 1986.

[51]. Bassani G, Farruggia B, Nerli B, Romanini D, Picó G. Porcine pancreatic lipase partition in potassium phosphate-polyethylene glycol aqueous two-phase systems. J. Chromatogr. B. 2007; 859:222-228.

[52]. Yavari M, Pazuki GR, Vossoughi M, Mirkhani SA, Seifkordi AA. Partitioning of alkaline protease from Bacillus licheniformis (ATCC 21424) using PEG- $\mathrm{K}_{2} \mathrm{HPO}_{4}$ aqueous two-phase system. Fluid Phase Equilibr. 2013; 337:1-5.

[53]. Cláudio AFM, Freire MG, Freire CSR, Silvestre AJD, Coutinho JAP. Extraction of vanillin using ionic-liquid-based aqueous two-phase systems. Sep. Purif. Technol. 2010; 75:39-47. 

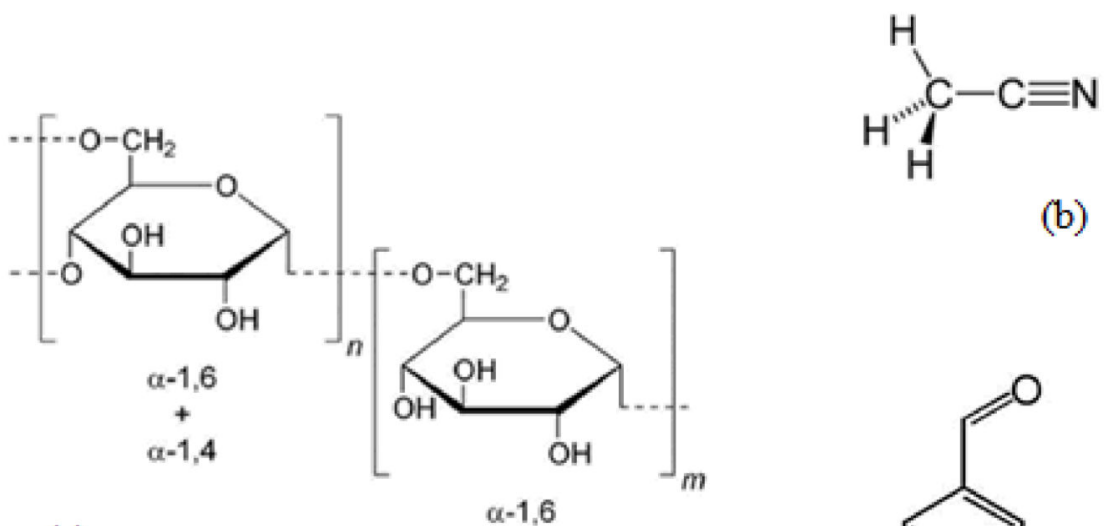

(a)

(b)

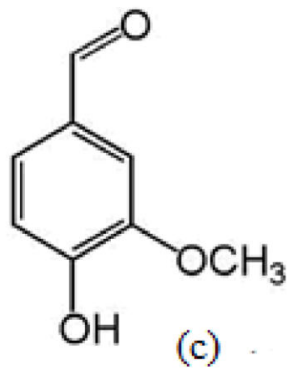

Figure 1.

Chemical structures of the phase-forming components used in the ATPS formation and of the biomolecule used as a partitioning solute: (a) dextran; (b) acetonitrile; (c) vanillin. 


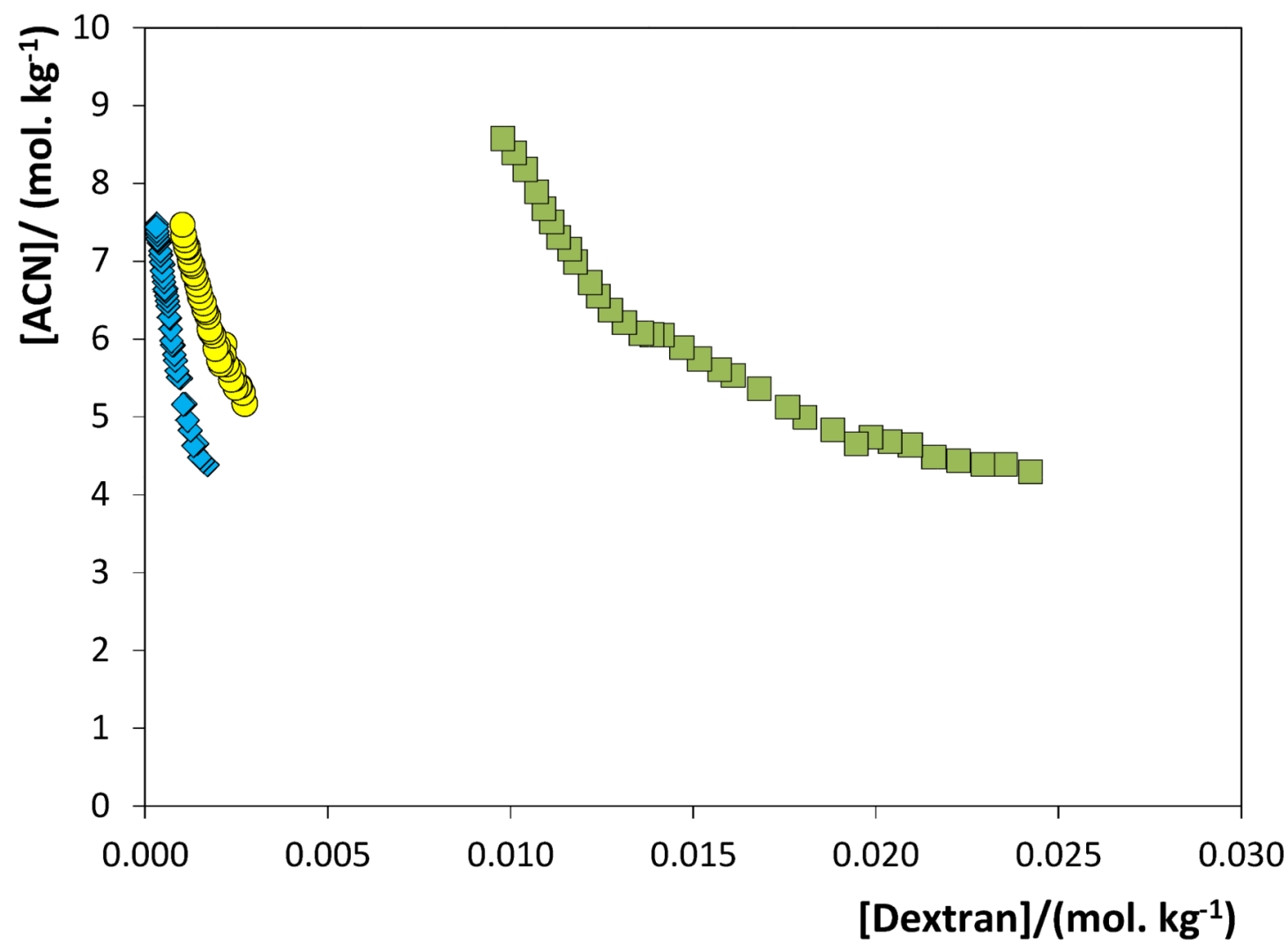

Figure 2.

Binodal curves (in molality) for the ternary systems composed of dextran + acetonitrile +

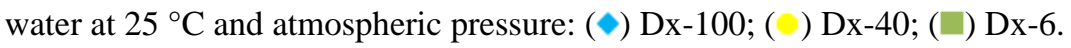




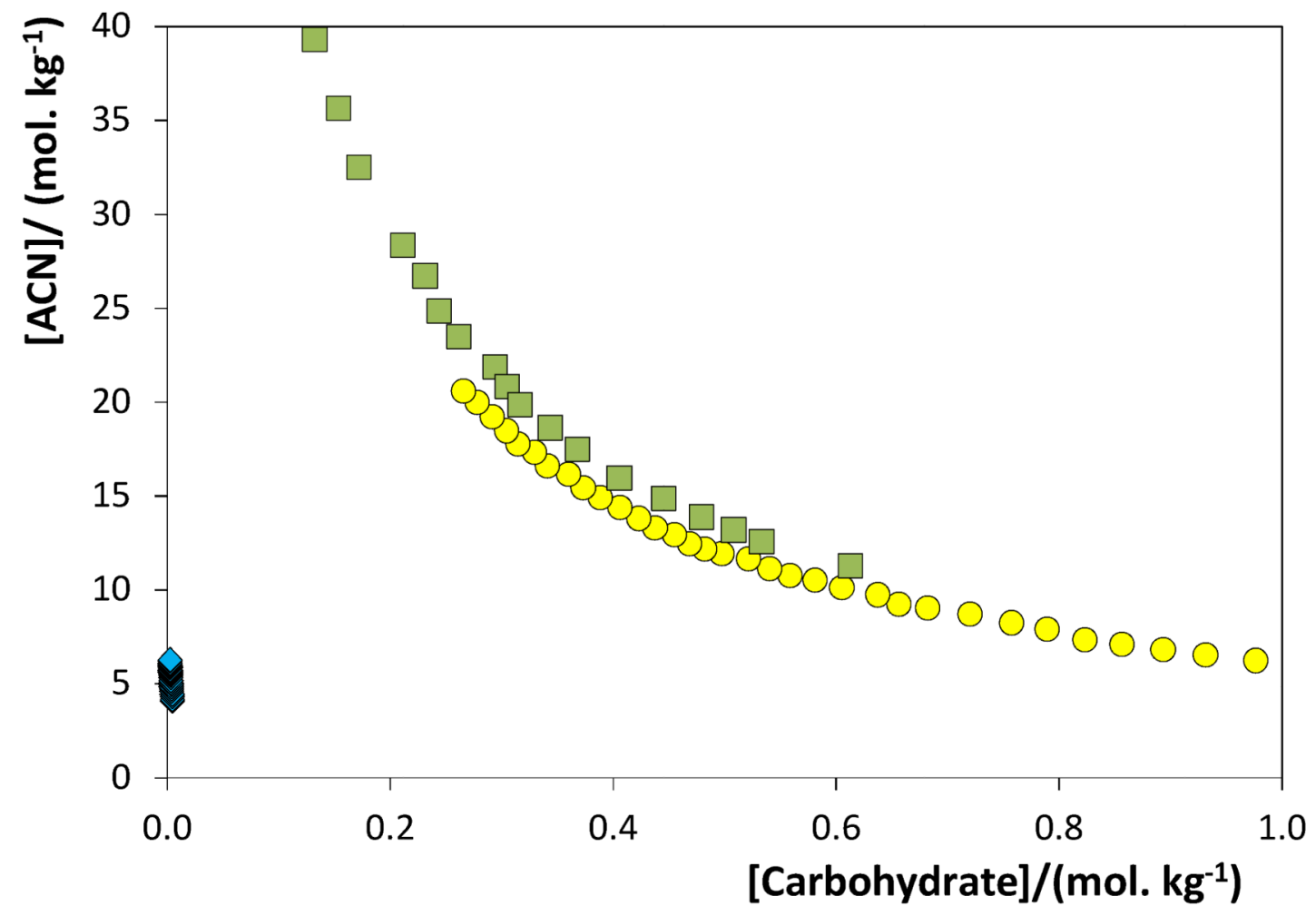

Figure 3.

Binodal curves (in molality) for the ternary systems composed of acetonitrile + carbohydrates at $25^{\circ} \mathrm{C}$ and atmospheric pressure: $(\diamond)$ dextran; ( ) maltitol [28]; $(\square)$ maltose [27]. 


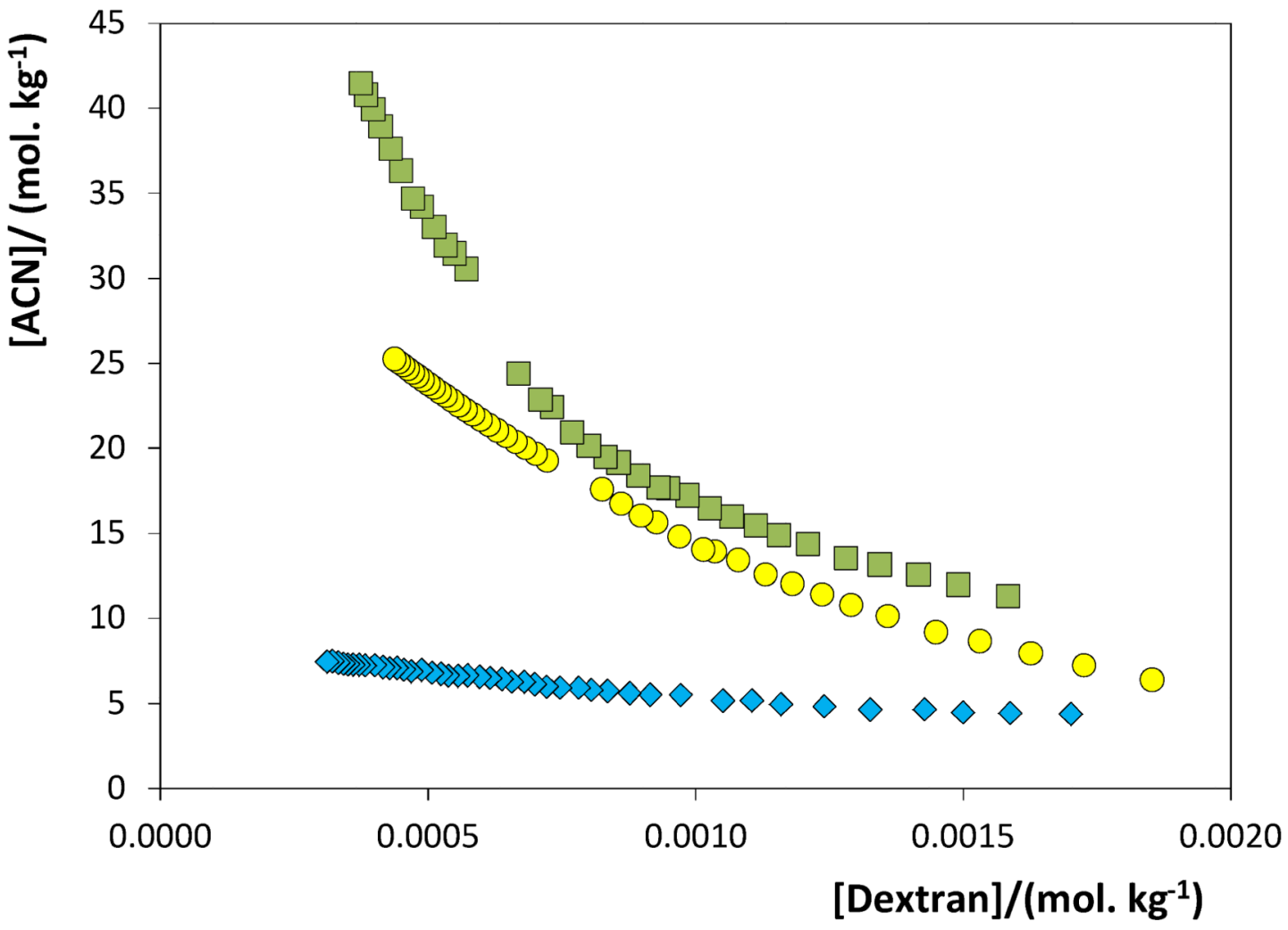

Figure 4.

Binodal curves (in molality) for the ternary systems composed of Dx-100 + acetonitrile + water at atmospheric pressure: $(\diamond) 25^{\circ} \mathrm{C}$; $(\odot) 35^{\circ} \mathrm{C}$; (口) $45^{\circ} \mathrm{C}$. 


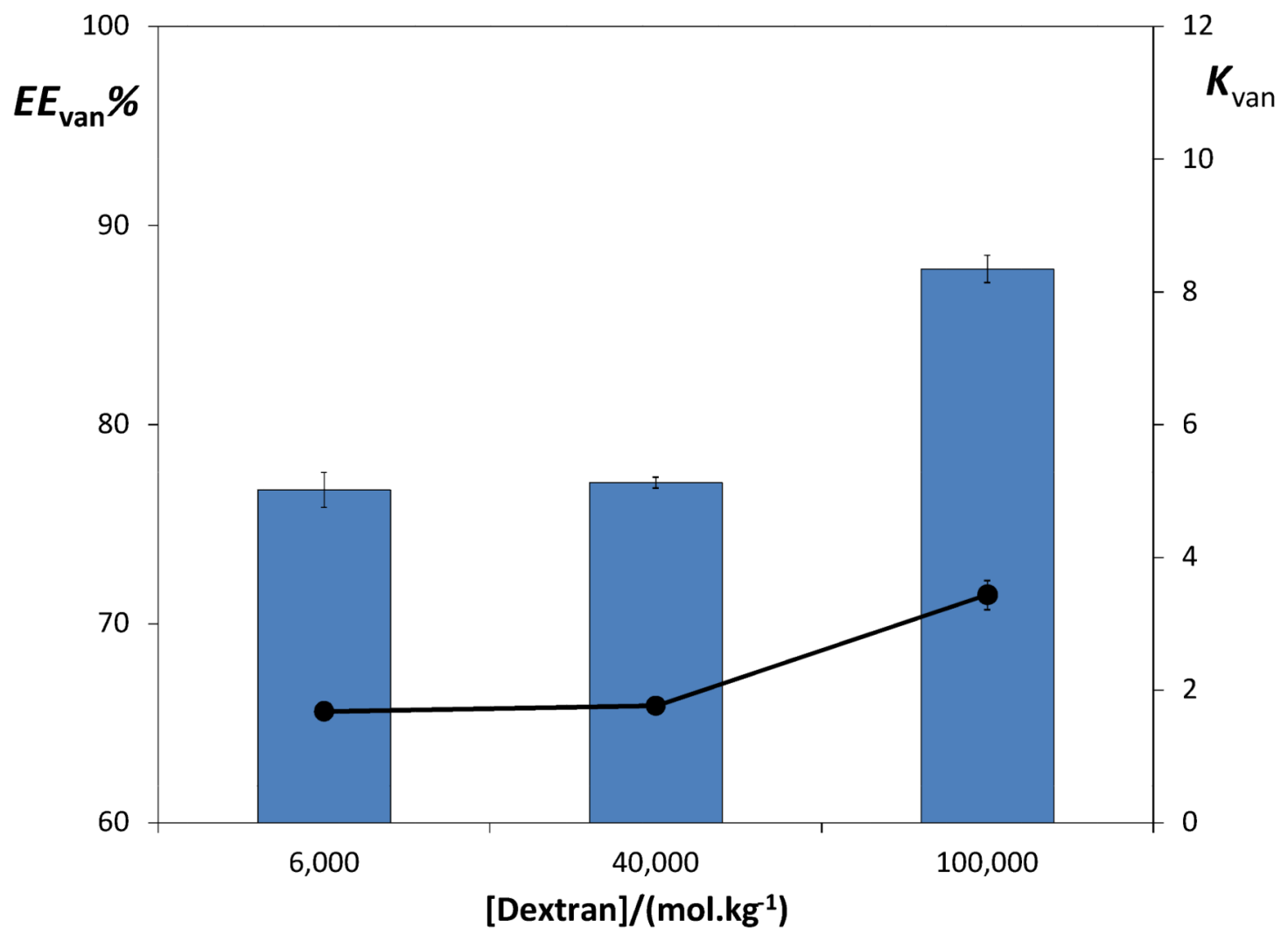

Figure 5.

Effect of the dextran molecular weight on the vanillin partitioning at $25^{\circ} \mathrm{C}$ for the system composed of dextran $(15 \mathrm{wt} \%)+$ acetonitrile $(30 \mathrm{wt} \%)$ for the acetonitrile-rich phase. Bars extraction efficiency $\left(E E_{\mathrm{van}} \%\right)$; symbols - partition coefficient $\left(K_{\mathrm{van}}\right)$. 

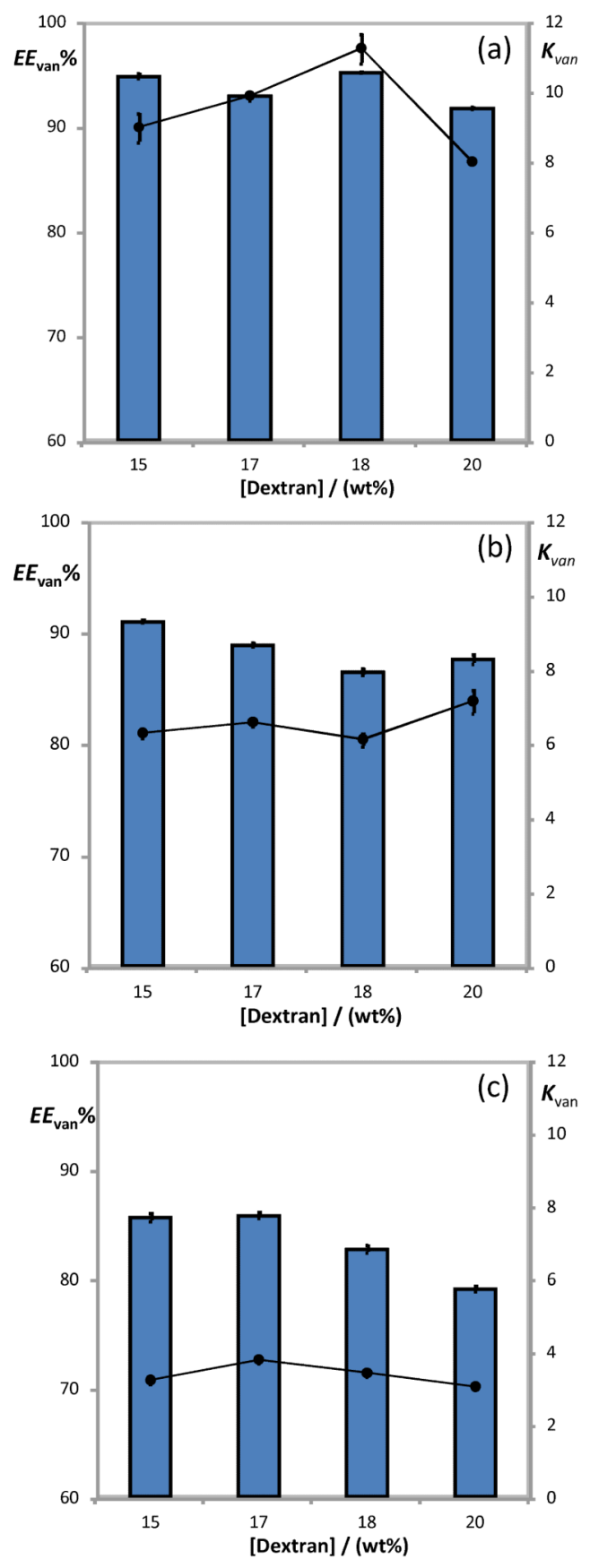

Figure 6.

Effect of the dextran concentration on the vanillin partitioning (Bars: extraction efficiency $E E_{\text {van }} \%$; symbols: partition coefficient $-K_{\text {van }}$ ) for the acetonitrile-rich phase at $25^{\circ} \mathrm{C}$ for the system composed of Dx-100 (15-20wt\%) + fixed concetrations of acetonitrile: ACN at 35 wt\% (blue bars and $\mathbf{\Delta}$ ); $\mathrm{ACN}$ at $30 \mathrm{wt} \%$ (green bars and $\boldsymbol{\square}$ ); ACN at $25 \mathrm{wt} \%$ (yellow bars and $\mathbf{O}$ ). 

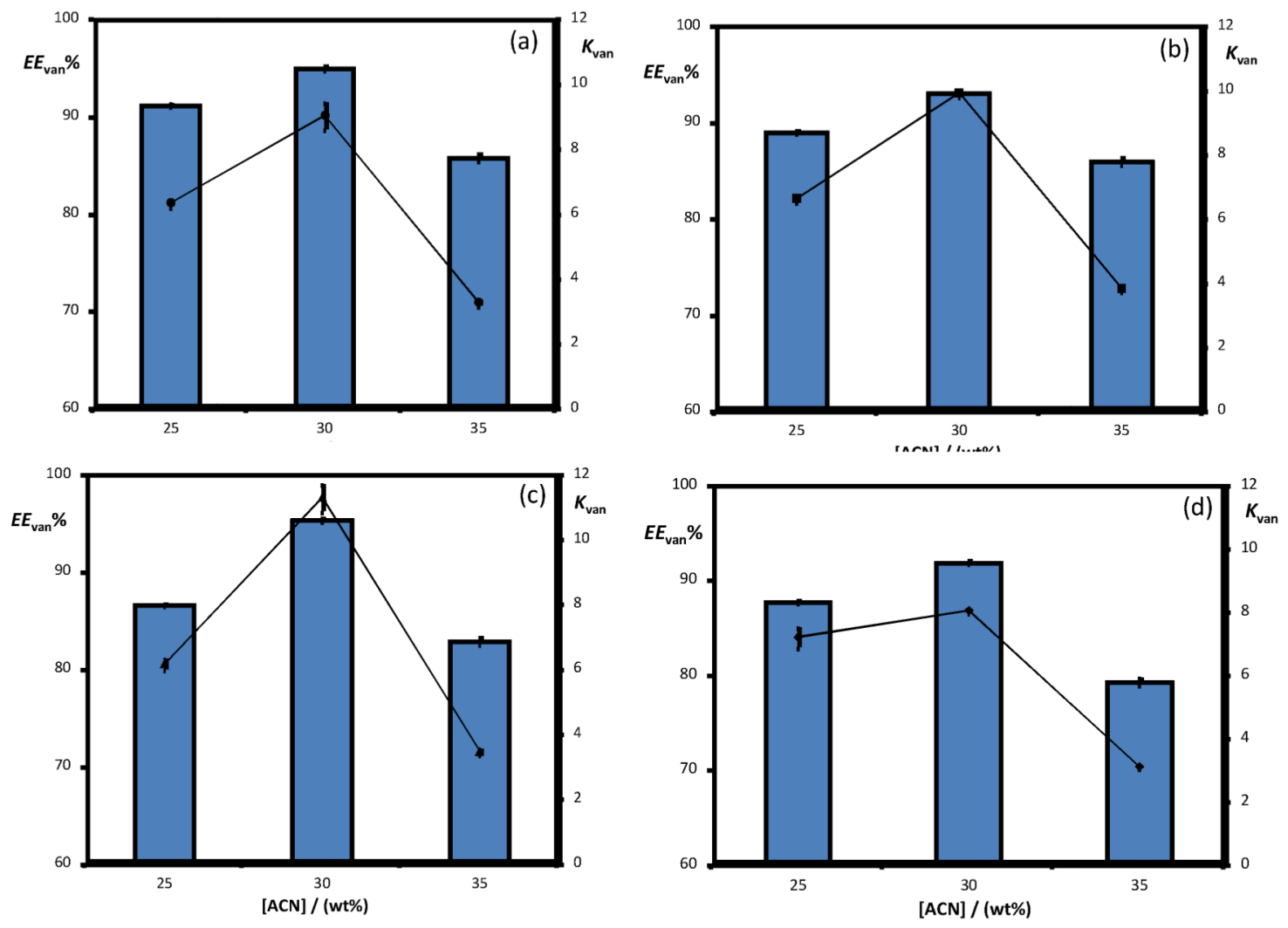

Figure 7.

Effect of the acetonitrile concentration on the vanillin partitioning for the acetonitrile-rich phase at $25{ }^{\circ} \mathrm{C}$ for the system composed of ACN (25-35 wt \%) + fixed concetrations of dextran: (a) dextran at $15 \mathrm{wt} \%$; (b) dextran at $17 \mathrm{wt} \%$; (c) dextran at $18 \mathrm{wt} \%$; (d) detxran at 20 wt. Bars - extraction efficiency $\left(E E_{\mathrm{van}} \%\right)$; symbols - partition coefficient $\left(K_{\mathrm{van}}\right)$. 


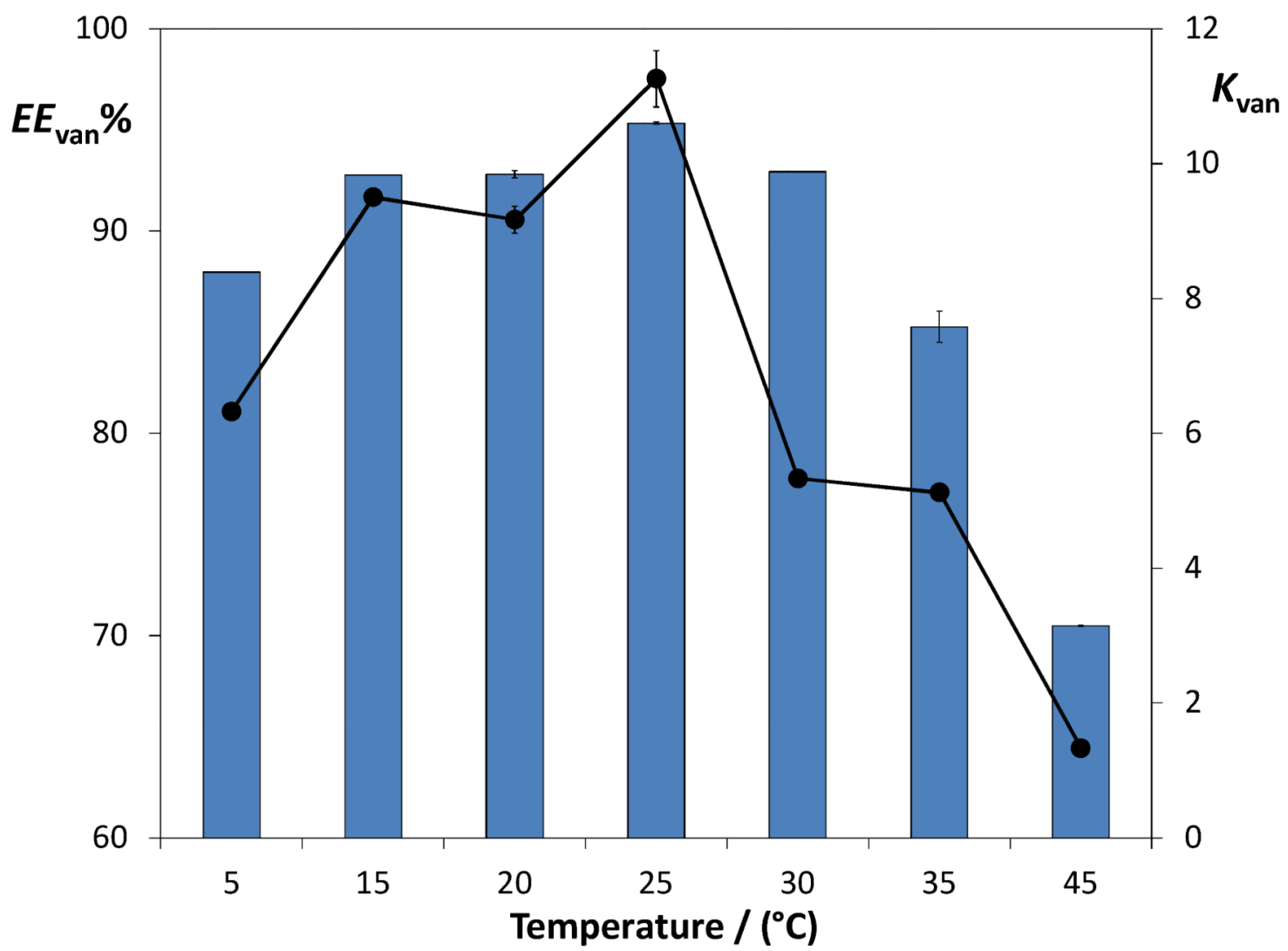

Figure 8.

Effect of temperature on the vanillin partitioning for the acetonitrile-rich phase for the system composed of Dx-100 (18 wt\%) + acetonitrile (30 wt\%). Bars - extraction efficiencies $\left(E E_{\mathrm{van}} \%\right)$; symbols - partition coefficients $\left(K_{\mathrm{van}}\right)$. 


\section{Table 1}

Correlation parameters used to describe the experimental binodal data by Eq. 1 and respective standard deviations $(\sigma)$ and correlation coefficients $\left(R^{2}\right)$.

\begin{tabular}{cccccc}
\hline Temperature & Dextran & $\boldsymbol{A} \pm \boldsymbol{\sigma}$ & $\boldsymbol{B} \pm \boldsymbol{\sigma}$ & $\boldsymbol{C} \pm \sigma$ & $\boldsymbol{R}^{\mathbf{2}}$ \\
\hline \multirow{3}{*}{$25^{\circ} \mathrm{C}$} & $6.000 \mathrm{~g} \cdot \mathrm{mol}^{-1}$ & $77.11 \pm 10.89$ & $-0.47 \pm 0.05$ & $3.97 \mathrm{E}^{-15} \pm 4.24 \mathrm{E}^{-5}$ & 0.9722 \\
\cline { 2 - 6 } & $40.000 \mathrm{~g} \cdot \mathrm{mol}^{-1}$ & $38.12 \pm 1.20$ & $-0.24 \pm 0.01$ & $1.61 \mathrm{E}^{-13} \pm 2.09 \mathrm{E}^{-5}$ & 0.9851 \\
\cline { 2 - 6 } & $100.000 \mathrm{~g} \cdot \mathrm{mol}^{-1}$ & $33.75 \pm 0.53$ & $-0.20 \pm 0.01$ & $2.03 \mathrm{E}^{-5} \pm 6.62 \mathrm{E}^{-6}$ & 0.9912 \\
\hline $35^{\circ} \mathrm{C}$ & $100.000 \mathrm{~g} \cdot \mathrm{mol}^{-1}$ & $94.45 \pm 2.10$ & $-0.28 \pm 0.01$ & $1.08 \mathrm{E}^{-4} \pm 5.25 \mathrm{E}^{-6}$ & 0.9993 \\
\hline $45^{\circ} \mathrm{C}$ & $100.000 \mathrm{~g} \cdot \mathrm{mol}^{-1}$ & $135.80 \pm 3.44$ & $-0.39 \pm 0.01$ & $1.33 \mathrm{E}^{-13} \pm 1.11 \mathrm{E}^{-5}$ & 0.9958 \\
\hline
\end{tabular}




\section{Table 2}

Mass fraction composition for the TLs and respective TLLs, at the top (T) and bottom (B) phases, and initial biphasic composition of the mixture $(\mathrm{M})$, for the systems composed of acetonitrile $(Y)$ and dextran $(X)$ at $25-45^{\circ} \mathrm{C}$.

\begin{tabular}{|c|c|c|c|c|c|c|c|c|}
\hline \multicolumn{9}{|c|}{ Weight fraction composition / wt \% } \\
\hline \multicolumn{9}{|c|}{ Acetonitrile + Dextran + water systems } \\
\hline Temperature & Dextran & $Y_{M}$ & $X_{\mathrm{M}}$ & $Y_{T}$ & $\boldsymbol{X}_{\mathbf{T}}$ & $Y_{\mathbf{B}}$ & $X_{\mathbf{B}}$ & TLL \\
\hline \multirow{6}{*}{$25^{\circ} \mathrm{C}$} & \multirow{2}{*}{$6.000 \mathrm{~g} \cdot \mathrm{mol}^{-1}$} & 29.92 & 10.14 & 46.56 & 1.12 & 8.26 & 21.88 & 53.42 \\
\hline & & 30.03 & 12.99 & 55.70 & 0.46 & 7.75 & 23.92 & 53.64 \\
\hline & \multirow{2}{*}{$40.000 \mathrm{~g} \cdot \mathrm{mol}^{-1}$} & 20.35 & 15.41 & 31.82 & 0.53 & 10.25 & 28.51 & 35.33 \\
\hline & & 20.00 & 10.03 & 29.12 & 1.19 & 14.58 & 15.28 & 20.24 \\
\hline & \multirow{2}{*}{100.000 g.mol ${ }^{-1}$} & 20.13 & 15.88 & 33.37 & 0.00 & 4.16 & 35.57 & 45.87 \\
\hline & & 22.50 & 10.00 & 31.08 & 0.17 & 5.54 & 32.06 & 40.85 \\
\hline \multirow{2}{*}{$35^{\circ} \mathrm{C}$} & \multirow{2}{*}{$100.000 \mathrm{~g} \cdot \mathrm{mol}^{-1}$} & 29.88 & 17.95 & 61.99 & 2.21 & 0.49 & 32.35 & 68.49 \\
\hline & & 30.98 & 15.53 & 60.43 & 2.48 & 1.72 & 28.50 & 64.22 \\
\hline \multirow{2}{*}{$45^{\circ} \mathrm{C}$} & \multirow{2}{*}{$100.000 \mathrm{~g} \cdot \mathrm{mol}^{-1}$} & 30.02 & 17.98 & 39.78 & 9.99 & 14.18 & 32.45 & 33.31 \\
\hline & & 39.54 & 14.86 & 51.34 & 6.02 & 13.16 & 34.64 & 47.72 \\
\hline
\end{tabular}

